\title{
Game Analysis of the Internal Control Information Disclosure of Listed Companies Based on Incomplete Information
}

\author{
Xiu-Qing ZANG ${ }^{1, a}$, Ting-Ting HAN ${ }^{1, b,}$, Juan $L V^{1, c}$ \\ ${ }^{1}$ School of Economic and Management, Yanshan University, Qinhuangdao, China \\ axqzang@126.com, bhantingting0328@163.com, 'masdfv@qq.com \\ ${ }^{*}$ Corresponding author
}

Keywords: Internal control information, Listed companies, Certified public accountants, Regulators; Game analysis.

\begin{abstract}
The laws and regulations issued by our government, to a certain extent, ensure the authenticity and completeness of the internal control information of listed companies. And promote the listed companies developing and implementing a sound and effective internal control system, thus avoiding the occurrence of fraud. From the angle of game, the disclosure of internal control information is a process of game between stakeholders. In this context, we construct an incomplete information dynamic game model of listed companies, certified public accountants and regulators and solve it by backward induction method. Several suggestions are provided for regulating the internal control information disclosure of listed companies.
\end{abstract}

\section{Problem Introduction and Research Significance}

In recent years, financial fraud and other violations keep emerging. The international giant conglomerates such as Enron, World Com and Lehman Brothers cannot avoid the fate of bankrupt because of this reason. Such cases also occur frequently in our country, mainly attribute to the serious flaws of internal control of listed companies. How to promote listed companies developing a sound internal control system and to motivate the effective implementation is increasingly becoming the focus of attention. At the same time, the government must act as the first responsible person. In recent years, CSRC and other relevant departments promulgated a series of laws and regulations about the internal control of listed companies on the basis of foreign-related system for reference. High attention is given to the internal control."Basic norms of internal control" known as the Chinese version of "Sarbanes-Oxley Act", jointly promulgated by the ministry of finance, the securities regulatory commission, the national audit office, the China banking regulatory commission, and insurance regulatory commission in 2008, marks the turning point of the construction of the internal control system in our country.[2]

The disclosure of internal control information is a process of game between stakeholders. The investors, relying on the internal control information acquired from listed companies, can more fully understand what the companies are. By this means, they can make right investment decisions and reduce investment risks, thus improving their confidence to the capital market.[3] In addition, the accuracy of internal control information is based on the effective internal control system. Therefore, we should supervise and urge the listed company to establish a complete, reasonable and effective internal control system, regulating the behavior of listed company internal personnel, which can avoid the occurring of financial fraud, so as to increase the information transparency of the capital market, to build a more perfect, healthy and sustainable development capital market. This paper, by studying the game of the internal control information disclosure, identifies the factors restricting the stakeholders and builds a incomplete information dynamic game model which is solved by backward induction. Suggestions are provided for driving the listed companies to disclose the internal control information truly. This study has very important theoretical and practical significance. 


\section{Game Model Assumptions}

\section{Model assumptions}

Hypothesis1: All stakeholders are rational economic person, who pursue their maximal interests.[1]

Hypothesis2: The listed companies are tending to disclose the information benefiting to themselves. If the internal control is effective, they will disclose the internal control information truly. Otherwise, they will disclose the false information.

Hypothesis3: The listed companies can gain excess profits when they disclose what is not true.

Hypothesis4: The listed company may bribe the CPAs, when their false internal control information is reviewed by them. At this time, the CPAs, in order to gain additional revenue, may not issue independent audit opinion. And this is auditing collusion.

Hypothesis5: The CPAs will adopt audit strategies which qualities are different for various companies. In general, the cost of high-quality audit strategies is lower than the low-quality audit strategies.[2]

Hypothesis6: The CSRC will review internal control information disclosed by listed companies randomly. The company that is found disclosing false information will be given administrative punishment.

Hypothesis7: The review technology of CSRC is limited. So it is possible that the company discloses false information cannot be found. Whether find it or not decided by nature.

\section{Players}

This game model has four players which are listed companies, external auditors, CSRC and other regulatory authorities and nature. Let the set of players be $\mathrm{I}=\{1,2,3, \mathrm{~N}\}, 1$ denotes listed companies, 2 denotes external auditors, 3 denotes CSRC, and 4 denotes nature.

\section{Strategy set of players}

Let $\mathrm{S}$ be the strategy set of players, $S_{a b k}$ denotes the k-th action in the b-th game stage of player a.So $S_{111}=$ true disclosure, $S_{112}=$ false disclosure, $S_{221}=$ high-quality auditing, $S_{222}=$ low-quality auditing, $S_{231}=$ independent opinion, $S_{232}=$ not independent opinion, $S_{341}=$ review, $S_{342}=$ not review, $S_{N 51}=$ find out, $S_{N 52}=$ not find out.[1]

\section{Parameter settings}

$V$ :The profit that listed companies can get when they disclose internal control information truly;

$v$ :The excess profit that listed companies can get when they disclose internal control information falsely;

$D$ :The audit fees that listed companies pay to the accounting firm, under normal circumstances;

$d$ :The additional audit fees that listed companies pay to the accounting firm, when auditing collusion exists;

$C$ :The audit cost when the CPAs adopt low-quality audit strategies;

$c$ :The excess audit cost when the CPAs adopt high-quality strategies rather than low-quality strategies;

$F:$ The review cost of regulators;

$J$ :The punishment that listed companies exerted to the CPAs, when they issue independent audit opinion. Namely, the CPAs will lose the auditing and other related business of the company in the following years;

$L_{1}$ :The listed companies will be faced with significance losses ,such as stock price falling sharply, financial difficulty and the lose of reputation. Just because the listed companies disclose internal control information truly, when there is design defect or operation defect in their internal control system; 
$L_{2}$ :The penalty that the listed companies disclose the information falsely punished by CSRC and other regulator departments;

$K_{1}$ :The deficiency of honesty and credit of auditing because the CPAs are investigated caused by auditing collusion;

$K_{2}$ :The penalty that the CPAs conspired with listed companies punished by CICPA and other regulator departments;

$r$ :denotes the possibility that the listed companies disclose internal control information truly, and 1-r denotes the possibility that the listed companies disclose internal control information falsely;

$P_{1}$ :denotes the possibility that the CPAs adopt high-quality audit strategies, and $1-P_{1}$ denotes the possibility that the CPAs adopt low-quality audit strategies;

$P_{2}$ :denotes the possibility that the CPAs issue independent opinion, and $1-P_{2}$ denotes the possibility that the CPAs conspired with the listed companies;

$P_{3}$ :The possibility that the listed companies are chosen by the CSRC and CICPA and other regulator departments. They adopt the random inspection method to review the internal control information;

$P_{4}$ :The possibility that auditing conclusion is found by regulators.

\section{The establishment and analysis of game model}

In the first stage of the game, the listed company choose whether disclose the internal control information truly or not; the second stage, the accounting firm which is hired estimates the quality of audit; the third stage, CPAs decide to issue an independent audit opinion or accept the bribes of listed companies and issue a not independent audit opinion, when they find the manipulation of accounts; the forth stage, is a process of internal control information and audit opinion random inspection by the government regulators. The listed companies can be selected or not; in the last stage, the government regulators will review the selected companies, but it is not absolutely that the problem can be found, and it is determined by nature. So in this paper, we construct a incomplete information dynamic game model of three players which is more than one stage. The following expressions are the revenue function of each stakeholder.

(1) $\left(S_{111}, S_{221}, S_{231}, S_{341}\right)=(V-B, D-C-c,-F)$

(2) $\left(S_{111}, S_{221}, S_{231}, S_{342}\right)=(V-B, D-C-c, 0)$

(3) $\left(S_{111}, S_{222}, S_{231}, S_{341}\right)=(V-B, D-C,-F)$

(4) $\left(S_{111}, S_{222}, S_{231}, S_{342}\right)=(V-B, D-C, 0)$

(5) $\left(S_{112}, S_{221}, S_{231}\right)=\left(V+\mathrm{v}-B-L_{1}, D-C-c-J, 0\right)$

(6) $\left(S_{112}, S_{221}, S_{232}, S_{341}, S_{N 51}\right)=\left(V+\mathrm{v}-B-L_{1}-L_{2}-d, D+d-C-c-K_{1}-K_{2}, L_{2}+K_{2}-F\right)$

(7) $\left(S_{112}, S_{221}, S_{232}, S_{341} S_{N 52}\right)=(V+v-B-d, D+d-C-c,-F)$

(8) $\left(S_{112}, S_{221}, S_{232}, S_{342}\right)=(V+v-B-d, D+d-C-c, 0)$ 
(9) $\left(S_{112}, S_{222}, S_{231}\right)\left(V+\mathrm{v}-B-L_{1}, D-C-J, 0\right)$

$(10)\left(S_{112}, S_{222}, S_{232}, S_{341} S_{N 51}\right)=\left(V+\mathrm{v}-B-L_{1}-L_{2}-d, D+d-C-K_{1}-K_{2}, L_{2}+K_{2}-F\right)$

(11) $\left(S_{112}, S_{222}, S_{232}, S_{341} S_{N 52}\right)=(V+v-B-d, D+d-C,-F)$

(12) $\left(S_{112}, S_{222}, S_{232}, S_{342}\right)=(V+v-B-d, D+d-C, 0)$

In this paper, we use backward induction method to solve the perfect Bayesian equilibrium. The followings are equilibrium results:

\section{The condition that CPAs adopt high-quality audit strategies}

(1)The expected revenue that the CPAs adopt high-quality audit strategies is $E\left(U_{2}\left(S_{221}\right)\right)$ :

$$
\begin{aligned}
& r P_{2}(D-C-c)+(1-r)\left\{P_{2}(D-C-c-J)+\left(1-P_{2}\right) P_{3}\left[P_{4}(D+d-C-c\right.\right. \\
& \left.\left.\left.-K_{1}-K_{2}\right)+\left(1-P_{4}\right)(D+d-C-c)\right]+\left(1-P_{2}\right)\left(1-P_{3}\right)(D+d-C)\right\}
\end{aligned}
$$

(2)The expected revenue that the CPAs adopt low-quality audit strategies is $E\left(U_{2}\left(S_{222}\right)\right)$ :

$$
\begin{aligned}
& r P_{2}(D-C)+(1-r)\left\{P_{2}(D-C-J)+\left(1-P_{2}\right) P_{3}\left[P_{4}\left(D+d-C-K_{1}-K_{2}\right)\right.\right. \\
& \left.\left.+\left(1-P_{4}\right)(D+d-C)\right]+\left(1-P_{2}\right)\left(1-P_{3}\right)(D+d-C)\right\}
\end{aligned}
$$

The condition that the CPAs prefer high-quality strategies to low-quality is:

$$
E\left(U_{2}\left(S_{221}\right)\right)>E\left(U_{2}\left(S_{222}\right)\right)
$$

After reorganization:

$$
r P_{2}+(+r)<0
$$

We can know that the parameter $P_{2}$ is between 0 and 1 from the above formula. On the condition that other variables are unchanged, the greater the value of $P_{2}$, the more is the CPAs, inclined to take the high-quality audit strategy.

The impact of variable $r$ on the above formula can be known by taking a derivative: let

$$
f_{1}=r P_{2}+(1-r)
$$

The derivative of function $f_{1}$ with respect to $\mathrm{r}$ is:

$$
P_{2}-1<0
$$

So function $f_{1}$ is decreasing function of $\mathrm{r}$. The larger the probability of listed companies disclose the information truly, the lager the expected revenue that the CPAs adopt the high-quality audit strategies. And they will be more inclined to take the high-quality audit strategy. 
So we can draw the conclusion that the larger the probability of audit independent as well as the listed companies disclose internal control information truly, the larger the probability that the CPAs adopt high-quality audit strategies.

\section{The condition that CPAs issue independent opinion}

(1)The expected revenue that the CPAs issue independent audit opinion is $E\left(U_{2}\left(S_{231}\right)\right)$ :

$$
r\left[P_{1}(D-C-c)+\left(1-P_{1}\right)(D-C)\right]+(1-r)\left[P_{1}(D-C-c-J)+\left(1-P_{1}\right)(D-C-J)\right]
$$

(2)The expected revenue that the CPAs conspire with the listed companies is $E\left(U_{2}\left(S_{232}\right)\right)$ :

$$
\begin{aligned}
& P_{1}\left\{P_{3}\left[P_{4}\left(D+d-C-c-K_{1}-K_{2}\right)+\left(1-P_{4}\right)(D+d-C-c)\right]+\left(1-P_{3}\right)(D+d-C-c)\right\} \\
& +\left(1-P_{1}\right)\left\{P_{3}\left[P_{4}\left(D+d-C-K_{1}-K_{2}\right)+\left(1-P_{4}\right)(D+d-C)\right]+\left(1-P_{3}\right)(D+d-C)\right\}
\end{aligned}
$$

The condition that the CPAs prefer to issue independent audit opinion is $E\left(U_{2}\left(S_{231}\right)\right)>E\left(U_{2}\left(S_{232}\right)\right)$

After reorganization:

$$
(1-r) J-P_{3} P_{4}\left(K_{1}+K_{2}\right)+d<0
$$

The conclusion is that audit independent is proportional to the possibility that listed companies disclose information truly, the review and found out possibility of regulators, and the losses of reputation and penalty caused by auditing collusion. In addition, audit independent is inversely proportional to the brides given to CPAs for audit collusion.

\section{The condition that the regulators choose its strategies}

The expected revenue that the regulators review the companies is $E\left(U_{3}\left(S_{341}\right)\right)$ :

$$
r\left[P_{1} P_{2}(-F)+\left(1-P_{1}\right) P_{2}(-F)\right]+(1-r)\left\{\left(1-P_{2}\right)\left[P_{4}\left(L_{2}+K_{2}-F\right)+\left(1-P_{4}\right)(-F)\right]\right\}
$$

The expected revenue that the regulators do not review the companies is 0 .

The condition that the regulators prefer to adopt the review strategy is:

$$
E\left(U_{3}\left(S_{341}\right)\right)>0
$$

After reorganization:

$$
-r F P_{2}+(1-r)\left(1-P_{2}\right)\left(P_{4} L_{2}+P_{4} K_{2}-F\right)>0
$$

The conclusion is that we can increase the possibility that the government regulator departments review the listed companies by the following means. For example increasing the review quality by improving the technology and experience of government regulators; increasing the legal penalty of the listed companies and the CPAs; decreasing the cost of review. In addition, the possibility that the CPAs conspire with the listed companies will increase when the fines of listed companies and CPAs is larger than the cost of review. And in this condition, the possibility that the government regulators review the internal control information should increase. 


\section{The condition that the listed companies disclose the internal control information truly}

The expected revenue that the listed companies disclose the information truly is:

$$
V-B
$$

The expected revenue of the listed companies when they disclose information falsely but the CPAs adopt high-quality strategies is $E\left(U_{1}\left(S_{112}, S_{221}, S_{-1}\right)\right)$ :

$$
\begin{aligned}
& P_{2}\left(V+v-B-L_{1}\right)+\left(1-P_{2}\right)\left\{P_{3}\left[P_{4}\left(V+v-B-L_{1}-L_{2}-d\right)+\left(1-P_{4}\right)(V+v-B-d)\right]\right. \\
+ & \left.\left(1-P_{3}\right)(V+v-B-d)\right\}
\end{aligned}
$$

The expected revenue of the listed companies when they disclose information falsely but the CPAs adopt low-quality strategies is $E\left(U_{1}\left(S_{112}, S_{222}, S_{-1}\right)\right)$ :

$$
\begin{aligned}
& P_{2}\left(V+v-B-L_{1}\right)+\left(1-P_{2}\right)\left\{P_{3}\left[P_{4}\left(V+v-B-L_{1}-L_{2}-d\right)+\left(1-P_{4}\right)(V+v-B-d)\right]\right. \\
& \left.+\left(1-P_{3}\right)(V+v-B-d)\right\}
\end{aligned}
$$

Obviously drawn:

$$
E\left(U_{1}\left(S_{112}, S_{221}, S_{-1}\right)\right)=E\left(U_{1}\left(S_{112}, S_{222}, S_{-1}\right)\right)
$$

The condition that the listed companies disclose the internal control information truly is:

$$
E\left(U_{1}\left(S_{112}, S_{221}, S_{-1}\right)\right)=E\left(U_{1}\left(S_{112}, S_{222}, S_{-1}\right)\right)<V-B
$$

After reorganization:

$$
{ }_{2} v_{1} P \#\left(1-{ }_{2}\right) P-d \quad P P L_{-1} \quad P P L_{2}<0
$$

The conclusion is that the larger $P_{2}$, the more is the listed companies, inclined to disclose the information falsely when $L_{1}<d$. Otherwise they are prefer to disclose the true information. The greater the parameter $L_{1}$, the bigger the losses that related to the reputation and stock of the company, when the information that the internal control system exists defect is disclosed. The greater the parameter $d$, the more the money that the listed companies bride the CPAs. The greater the parameter $P_{3}$, the larger the possibility that the government regulator departments review the listed companies. The greater the parameter $L_{2}$, the more amount of penalty that the listed companies are punished by CSRC, the more they will be inclined to disclose information truly.

\section{Analysis of Game equilibrium}

According to the analysis of Game equilibrium, we can draw the conclusion that the process of internal control information disclosure is influenced by many factors in and out of the company. So this paper provides several suggestions to regulating the internal control information system of our country.

First of all, increasing the possibility of supervision and review by CSRC and at the same time reduce the review cost. The above game analysis shows that the lower review cost and greater 
possibility can enhance the listed company disclose the internal control information truly, thus creating sufficient conditions to improve the quality of independent audit. We can realize the goal of reduce cost by the following methods. First, for the government regulators, the idea of cost saving is as important as the concept of social benefit outweigh everything. They should increase efficiency and save cost in practical work. Secondly, the technical level and profession quality of regulators can be further improved by training. In one word, increasing the possibility of review which can avoid individual listed companies to escape by good fortune, and practically strengthen law enforcement, maintain the authority of audit.

Secondly, intensify the supervision and punishment by CSRC. The CSRC shall severely punish the incident that the listed companies conspire with CPAs. If the fines cannot amount to the addition revenue, the violation behaviors cannot be restricted and auditing conspiracy events will continue to happen. So the listed companies that disclose internal control self assessment report falsely and cause serious influence, should be punished without leniency and be investigated for their criminal responsibility according to the law. They should be given a higher amount of fines and at the same time confiscate the illegal income.

Finally, increase market supervision power. With the development of information era, the public increasingly focus their attention on state of operation of listed companies. The internal control information of listed companies can reach to each information demanders more convenient and quickly by the mean of information dissemination. So when the listed companies conspiring with CPAs disclose internal control information falsely and founded out by government regulators, combined with the enclosure by news media, they will be faced with severe punishment. The social opinion of the public will seriously damage their reputation. The consequence is the falling of stock price and financing difficulty which have adverse effects to company. For the accounting firm, the deficiency of reputation and integrity will cause the depression of business. The CPAs will prefer to independent audit to avoid reputation damage. Therefore, although the cost that the news media require information is low, it has a positive effect in the regulation of internal control information disclosure.

\section{References}

[1]Zhao Baoqing, Zhu Chanfei, Game analysis of audit quality control of certified public accountant, Accounting Research. 2009(4) 87-93.

[2]Song Shaoqing, Zhang Yao, Influence factors of internal control information disclosure: based on corporate governance, Communication of Fiance and Accounting. 2008(10) 88-91.

[3]Huang Zuping, Chen Yinsen, The cost-benefit analysis of internal control information disclosure in the listed companies, China Business and Market. 2008(11) 75-77.

[4]Zuo Wei, Qia Ye, Influence factors of internal control information disclosure: based on small\&medium private listed enterprises, Journal of Nanjing University of Aeronautics \&Astronautics (Social Sciences) . 2009(3) 32-40.

[5]Xiao Jun, Research on the governance effect of internal control information disclosure, Friend of Accounting. 2009(12) 101-102.

[6]Zhang Yongtao, Research on the quality of internal control information disclosure of Chinese listed companies. Jiang Su: Jiang Su University. 2009 7-40. 